\title{
The Threads that Bind Us
}

Charlotte Clemens and Irene Paulsen

\section{Victoria University}

\begin{abstract}
The Words and Pictures project aims to stimulate links between students in Australian schools and those from other nations. Through the process of sharing their drawings and stories, students develop a deeper understanding of each other's culture, beliefs and living conditions, as well as exploring their own modes of expression. This iteration of the project collected art work by students in the Solomon Islands, where the authors' personal connections to the location and history are also brought in to focus. A video of the project accompanies this article.
\end{abstract}

\section{Keywords}

children's art; intercultural dialogue; art education; Solomon Islands 


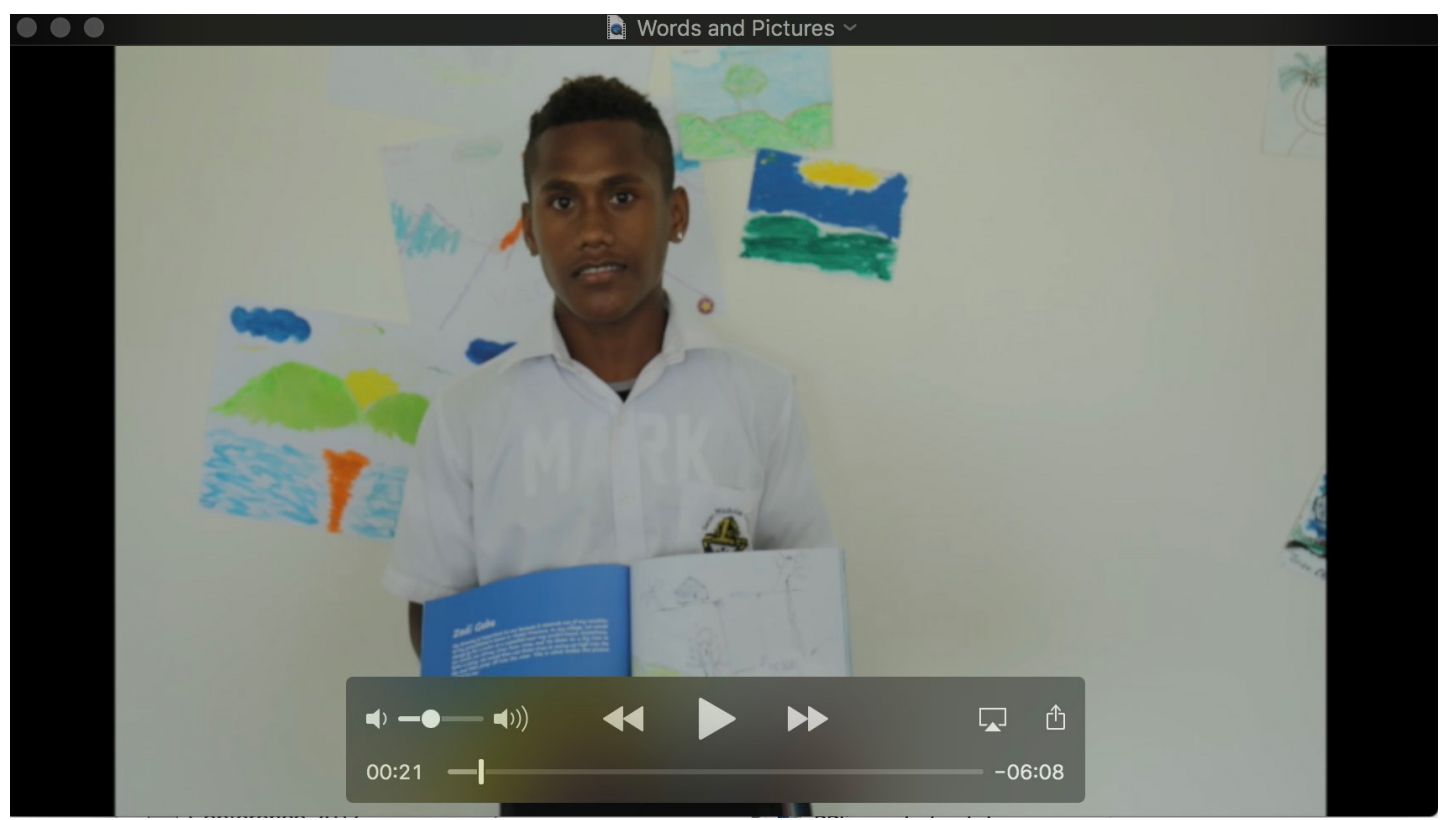

View the project video here: https://vimeo.com/297021472

\section{Words and Pictures}

The Words and Pictures project involves the collection and sharing of drawings and stories created by children and young people in different geographic locations, in each case culminating in an exhibition and publication of the students' work in book form. The project aims to stimulate connections and cultural understanding between students in Australian schools and those from other countries. The project undertaken in the Solomon Islands followed earlier projects featuring art work and stories from children in Sudan, Sri Lanka, India and China. In each case the books have been launched at an event that gave centre stage to an exhibition of the art works and the stories.

The Words and Pictures model originates from a concept developed and coordinated by Professor Maureen Ryan, Dr Sarah Tartakover and Debbie Qadri at Victoria University, Melbourne, Australia and is part of the ongoing activities of Gallery Sunshine Everywhere (www.gallerysunshine.com). Through the process of sharing drawings and stories prepared by students from other countries with students from Australia, the aim is to develop a deeper understanding of the student groups and each other's culture, beliefs and living conditions (See http://wordsandpicturesprojects.blogspot.com.au).

\section{Background to the Solomon Islands Project}

The idea of the Solomon Islands as a potential location for the project came about through a shared personal connection to this part of the world for both myself and my colleague Dr. Irene Paulsen, discovered while working together at the College of Education at Victoria University in Melbourne, Australia. As Irene is from the Solomon Islands, I was eager to find out if she knew anything about my father, Major Martin Clemens, who had spent the war years in Tulagi and Guadalcanal after an initial four years as district officer for the British Government. Irene explained that his story was taught in schools and considered a key part of Solomon Island history. This connection formed a developing bond between us that subsequently led us to initiate the Solomon Island Words and Pictures project. 
When Irene was planning to return to the Solomon Islands after gaining her $\mathrm{PhD}$, she invited me to accompany her. Through our shared contact with Professor Maureen Ryan, who coordinates the UNESCO funded Words and Pictures project, we were keen to collect pictures produced by Solomon Islands students if we had the opportunity and proposed that this could be included in the broader project.

Upon our arrival in Honiara, the capital of the Solomon Islands, we were interviewed by the Ministry of Education. While waiting for the project to move ahead we searched Honiara for art materials, soon discovering that this was harder than anticipated.

We learned that art is not studied at schools in the Solomon Islands, even though there is a thriving local art and craft industry. The purpose of art appears to be mainly restricted to the tourist industry, with this predominantly taking the form of reproducing traditional art. However when I spoke to artists and local business people, I came to understand that some local artists had come together to develop new designs for clothing and fabrics and some were interested in exploring other art forms.

While education is supposed to be compulsory in the Solomon Islands, it appears to be largely limited to those who can afford it, as many schools charge additional fees that may be expensive for some families. Families are often large, meaning that only some of the children can pursue a post-secondary education. Traditionally boys are educated first, while girls are mostly kept at home to assist with chores.

We took the opportunity to visit St. Nicholas College, as staff there had expressed interest in participating in the project. After a brief chat with the Principal, we were given an offer to work with a class of 30 boys at year eight level, as these students would otherwise have had no teacher for a couple of periods. We were introduced to the class by the Vice Principal and explained the project. The process would require each participating student

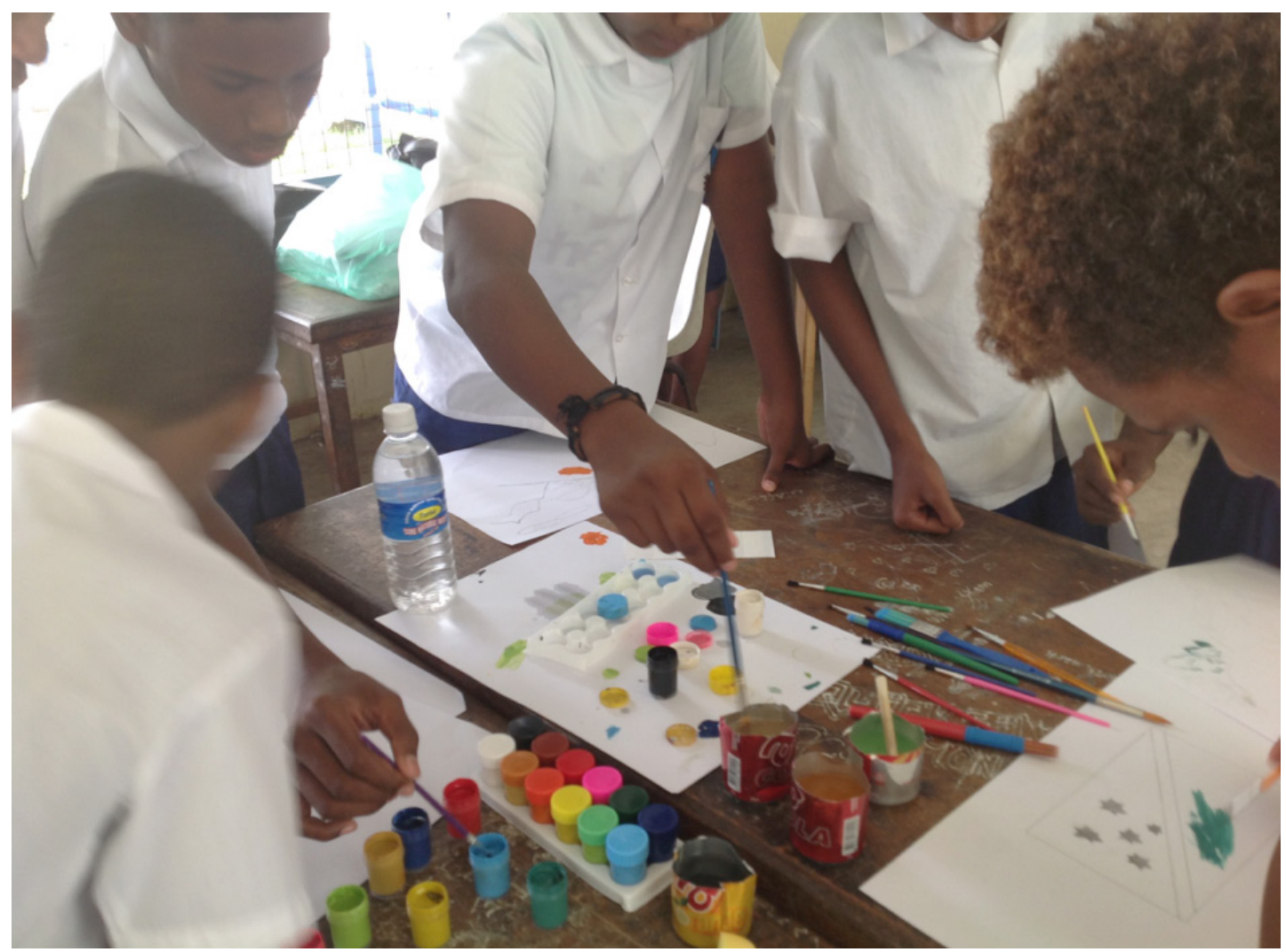

Figure 1: St Nicholas students at their paint station 


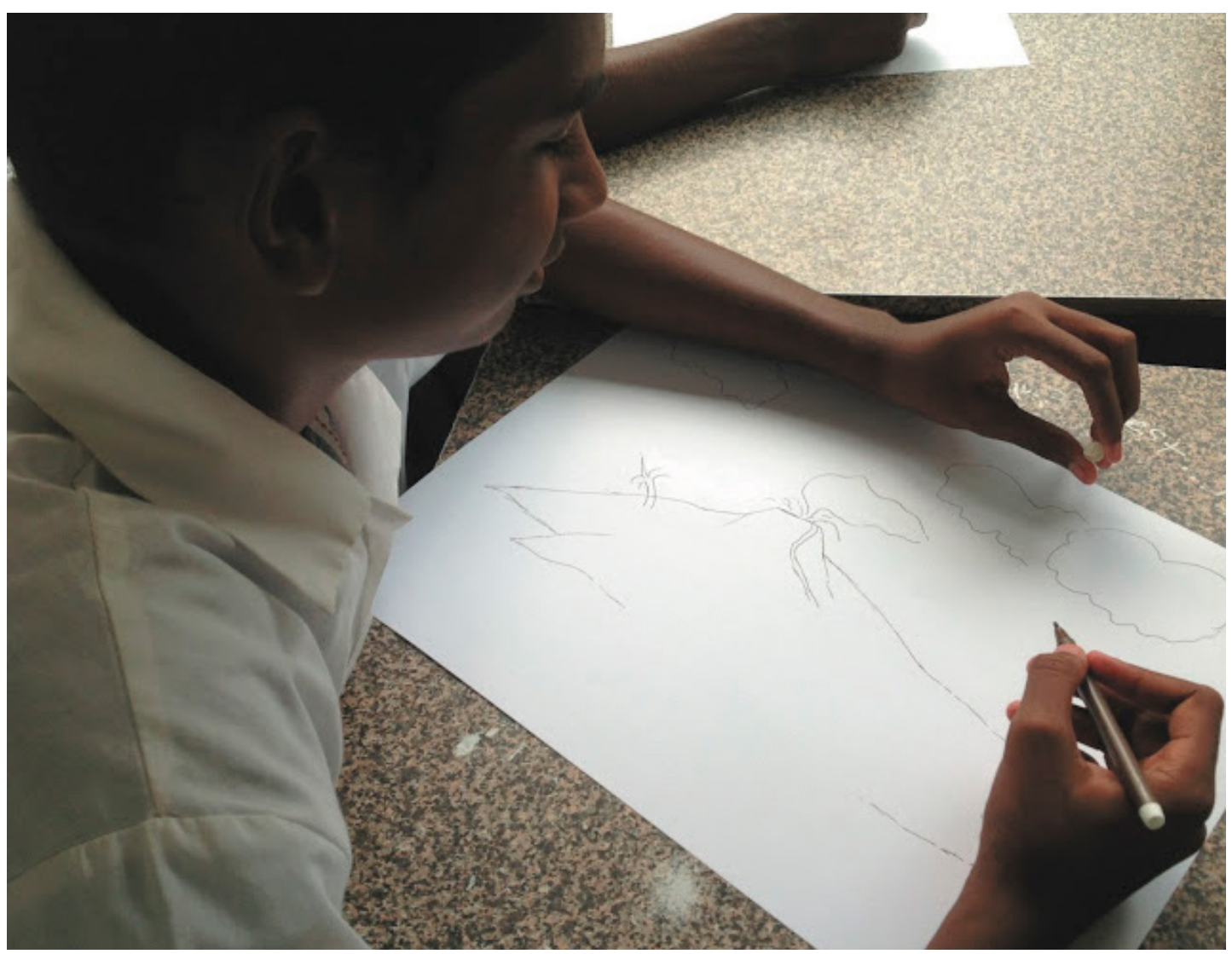

Figure 2:

A student draws a volcano; nature and the environment feature prominently in the students' work.

to create an art work so it could be taken back to Australia for students in Melbourne to respond in writing to the images they had made. We would then create books to send back to the Solomon Islands, documenting this response. When students were asked whether they wanted to participate in the project, nearly all of them agreed.

Ideas for topics were discussed with the class, and we settled on addressing what the students wanted Australian students to know about their country. Paint brush control, the order for drawing and painting and other technical issues were explored and demonstrated. Two work stations were established with paints and brushes and the students were invited to start drawing and painting.

We found that the students were far more skilled at drawing than anticipated, especially after discovering that the curriculum contained no arts component. Keen, shy and polite, they clearly took the project very seriously. At pack up time, students were clamouring to put finishing touches to their work and quietly refusing to stop. Even after monitors were assigned to assist in the clean up, it was hard to stop them.

Returning to Australia, the paintings and photographs were shared with the project leader Professor Maureen Ryan, who was enthusiastic about creating a book with the students' work. At a subsequent meeting with Dr. Siewfang Law and Dr. Sarah Tartakova, from the College of Arts and Education at Victoria University, it was suggested that a poster be made to thank the students and the school. Every piece of artwork was included and was combined with photos and the student names. As a final gesture we added a well known quote from Picasso as inspiration: 'Every child is an artist, the problem is how to remain an artist once they grow up'. 


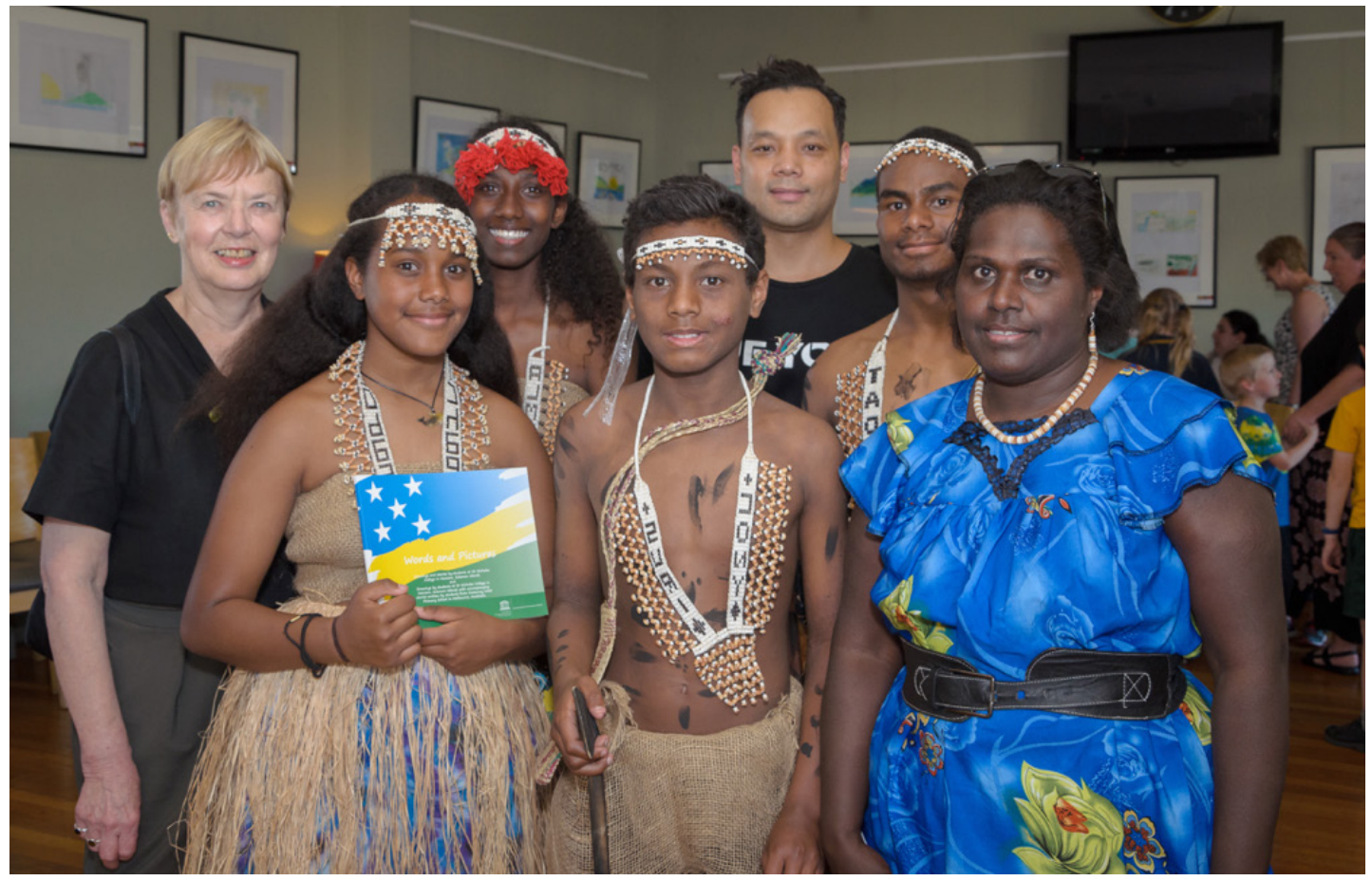

Figure 3 : Professor Maureen Ryan with the Solomon Island Dancers at Gallery Sunshine Everywhere, in Melbourne, Australia, where the book was initially launched.

\section{Book Launch in Honiara}

A year after our initial trip to the Solomon Islands, we returned to Honiara with the completed books, invitations and agendas for the launch to be organised on our arrival. The Australian embassy assisted us in our preparations for the event which became a significant occasion for everyone involved.

The school students, 29 boys and one girl, and five teachers including James Lengi, the new Principal, all attended. Others guests included: Ms. June Lilo, a representative from the Ministry of Education, two reporters from the Island Sun, two filmmakers making a video for the project, Louise Scott, who works in small business affairs for the Australian Embassy and Rebecca Spratt from Auckland University. Two representatives from the National Gallery were also invited in the hope that they could promote the positive aspects of learning and teaching the arts, and subsequently had productive talks with teachers about establishing an Art Club at the school.

The Deputy High Commissioner, Michael Hassett, was invited to say a few words and shake each student's hand, while he presented the books to them. We introduced and described the project, and spoke about the advantages of studying the arts. The Australian Deputy High Commissioner, followed, noting the value of projects that promoted links between countries, while the Principal of St.Nicholas College spoke to the value of this particular project. Slides of the Australian book Launch at Gallery Sunshine Everywhere in Melbourne, proved very popular with the Solomon Island students. A video of the Sunshine launch added to the excitement.

The strategy of inviting influential guests and the press, and holding the event in a well known venue, ensured that the occasion was a memorable one for teachers and students. Students who appeared on the video of the Solomon Island Launch said they 
were very proud and excited about having their work appear in the book. The teachers demonstrated great devotion and commitment to their students, with the Principal, James Lengi, speaking of his 'beautiful students' in his introductory presentation. We were also delighted to hear Mr. Lengi, mention in the video for the project that he felt the school curriculum needed to address the arts in future in order to satisfy the students' needs to have a variety of means of expressing their ideas.

Interest in the natural environment featured prominently in the work of students from the Solomon Islands. They were aware of the problems of pollution, plastics in the sea and the impact of logging. The students demonstrated great pride in their country and their flag, explaining what the colours and symbols represented and choosing to include these in their drawings. The Australian students in turn showed insatiable curiosity about the lives of the students in the Solomon Islands and the quality of their written responses demonstrates the relevance of the project for their own developing modes of expression.

We learned a great deal from our involvement in the project and feel privileged to have been part of a project that was received so well both in Australia and the Solomon Islands. Recently discovering that the Victorian Curriculum Assessment Authority has used the book as an example of what can be achieved through international relations, has been an additional rewarding outcome.

A digital version of the book can be viewed online at: http://wordsandpicturesprojects.blogspot.com/

The project video can be viewed online at: https://vimeo.com/297021472

\section{Acknowledgments}

The article was edited with the assistance of Gil Dwyer.

\section{About the Authors}

Charlotte Clemens is a Melbourne artist who has worked as a scenic artist, teacher and lecturer, in Australia and internationally. Her work reflects a particular interest in social realist art that offers a women's perspective of daily life and seeks to influence cultural attitudes. By maintaining art practice throughout, she has exhibited thirty seven times and founded Community Art Workers and Bad Mothers art groups. Her work is widely represented both in Australia and overseas.

Irene Paulsen is a teacher and lecturer who is currently working as Programme Manager for Auckland Uniservices Limited on a Leaders and Education Authorities programme. After teaching in Honiara, Guadalcanal, she emigrated to Australia with her three young children. She lectured in the College of Education at Victoria University for ten years before recently returning to the Solomon Islands. 